\title{
АКАДЕМИЧЕСКОЕ ПИСЬМО
}

DOI: https://doi.org/10.31992/0869-3617-2020-29-3-37-57

\section{Обзор обзоров как инструмент выявления трендов в исследуемой области знания}

\author{
Раицкая Иилия Климентовна - А-р пед. наук, канд. экон. наук, проф., советник ректора. \\ E-mail: raitskaya.1.k@inno.mgimo.ru \\ Московский государственный институт международных отношений (университет), Москва, \\ Россия
}

Адрес: 119454, г. Москва, проспект Вернадского, 76

Тихонова Елена Викторовна - канд. истор. наук, доцент. E-mail: etihonova@gmail.com

Российский университет дружбы народов, Москва, Россия

Адрес: 117198, г. Москва, ул. Миклухо-Маклая, 6

Российская академия образования, Москва, Россия

Адрес: 119121, г. Москва, ул. Погодинская, 8

Аннотачия. Авторь рассматривают методологчческие основания обзоров как перспективного вида научных публикачий, их таксономию и наиболее популярные виды обзоров (нарративный, библиометрический, системный, обзор обзоров, обзор предметного поля, метаанализ), а также особенности прочедур и алгоритмов их проведения. Обзор 100 самьх вьсокоцитируемьх обзоров по проблематике высшего образования за 2010-2019 г2., опубликованньхх в высокорейтинговых научных реиензируемых журналах, индексируемьх в международной базе Scopиs, составлен на основе традиционной методологии, челью которой является репрезентативный отбор наиболее значимых источников, контент-анализа, библиометрического и лингвистического анализа данного вида публикачий. Базируясь на соответствуюших критериях включения и ключевьх словах анализируемьх публикачий, авторь вьделяют основнье тематические кластеры в Топ-100 (образовательные технологии, университет, студент, преподавание, обучение, оченивание и др.) и определяют тенденчии в данной предметной области. Каждьй из тематических кластеров содержит описание основных подходов к проблематике высшего образования, анализ их новизны и существуюшие пробель в предметном поле. На основе риторической теории научного текста Аж. М. Свейлза авторами приводится обобщённая риторическая схема текста обзора, с комментариями по содержанию всех составньх частей, которая может стать практической рекомендаиией для авторов при подготовке обзоров в международные научные речензируемье журналь. Наиболее популярными по количеству чуитирований и количеству публикачий оказались обзоры, посвящённые культуре высшего образования, педагогическим технологиям и особенностям их применения в новом образовательном ландшафте, онлайн-образованию как новому измерению образования, требующему формирования особой экосистемь, академической этике преподавателей вузов, формированию компетениий, необходимьх для успешного профессионального развития, академическим и научным библиотекам как новым центрам коммуникачии.

Ключевые слова: обзор, систематический обзор, обзор предметного поля, библиометрический обзор, теоретический обзор, описательньй обзор, нарративньй обзор, высшее образование, университет, обучение, технологии 
Аля изитрования: Раицкая А.К., Тихонова Е.В. Обзор обзоров как инструмент выявления трендов в исследуемой области знания // Высшее образование в России. 2020. Т. 29. № 3. C. 37-57.

DOI: https://doi.org/10.31992/0869-3617-2020-29-3-37-57

\section{Введение}

Одной из главных задач современного исследователя является поиск релевантной информации, обладающей научной ценностью. В цифровую эпоху, когда часть функций по оценке любого контента переходит к потребителю информации, становятся востребованными общественные механизмы объективной оценки контента. Такими инструментами выступают международные наукометрические базы данных (Scopus, Web of Science, Medline и другие), индексация в которых, наряду с наименованием издателя, даёт представление читателю, какого качества следует ожидать от публикации. Регулярные пересмотры индексируемых научных периодических изданий и исключение из баз журналов, которые или не получают достаточного внимания со стороны сообщества (отсутствие цитирований), или проводят неэтичную редакционную политику (нарушения в процессе рецензирования, коммерциализация, неразборчивость в приёме рукописей), ставят целью поддержание репутации международных баз цитирования. Разумеется, индексация в Scopus и Web of Science не может быть абсолютной гарантией высокого качества публикаций.

В академической среде сложилось представление о высококачественных международных журналах как изданиях, которые поддерживают свою репутацию и публикуют результаты лучших научных исследований. Особое доверие исследователи испытывают к журналам, которые в дополнение к высоким показателям цитирования в крупнейших наукометрических базах, выпускаются уважаемыми международными издательствами (по рейтингу $\mathrm{SENSE}^{1}$ - это

1 The WASSMSENSE book publishers ranking list 2017. URL: http://www.sense.nl/organisation/documentation журналы и издательства категорий А и В). К ним относятся издательства лидеров мирового высшего образования - Кембриджского, Оксфордского, Гарвардского, Йельского университетов, а также крупные научные издательства - Elsevier, Springer Nature, Taylor \& Francis, Wiley, SAGE, Emerald.

Аля российской науки, в первую очередь её социогуманитарной части, проблема интернационализации стоит очень остро, ведь статьи отечественных учёных практически не представлены в ведущих международных журналах по образованию, философии, социологии, экономике, юриспруденции. В сопоставлении с мировыми трендами эта часть отечественной науки отличается локализацией дискурса, неактуальностью тематики, практически отсутствием вклада в науку исследований, опубликованных за последние 20-30 лет. Характерна оторванность российских учёных от мирового научного сообщества, в большинстве они не имеют представления о самых актуальных и важных исследованиях, редко регулярно знакомятся с публикациями в высококвартильных журналах, отличаются слабым продуктивным и даже репродуктивным владением английским языком. Одним из эфрфективных путей приобщения российских учёных к значимьм международным исследованиям, а также инструментом их ориентачии в передовых научных трендах могут стать обзорь, публикуемые на русском языке или на русском $u$ англииском языках в российских рецензируемьхх журналах.

\section{Методологическая часть.}

Что значит сделать хороший обзор?

Обзоры - один из самых перспективных типов научных публикаций, поскольку они основаны на использовании обоснованной методики и алгоритмов выбора источников, 
исключающих случайность и субъективность при их подготовке.

Рассматривая принятую в мире методологию этого типа исследований и методику составления обзоров, следует отметить их большое многообразие. Практически невозможно составить единую таксономию, так как на выбор методики влияют самые разные факторы. Обзоры могут классифицироваться в зависимости от литературных источников (например, теоретический), от стиля изложения (нарративный) или глубины анализа (метаанализ), от методологии обзора (систематический, библиометрический, метаанализ) и др. Часто обзоры совмещают в себе ряд функциональных подходов и обозначаются как «обзор». При этом авторы таких обзоров подробно описывают методику и процедуру проведения исследования в соответствующем разделе публикации.

Некоторые авторы [1] считают, что все произведения данного жанра могут быть сведены к двум видам. Во-первых, это традиционный нарративный, или несистематический, обзор; во-вторых, систематический обзор, который сопровождается или не сопровождается метаанализом. Аругие авторы выделяют до 14 видов обзоров [2]. Сложные формы обзоров препятствуют созданию чёткой и однозначной типологии [3]. Наиболее распространены следующие виды обзоров.

Нарративный, или описательный (англ. narrative or descriptive review) - исторически самый распространённый вид обзора. Основной характеристикой так называемого традиционного обзора является несистематичность - т.е. отсутствие предписанной методологии. Такой обзор представляет собой описание, часто хронологическое или на основании концепций/ теорий, научных школ. Такие описания характерны для диссертаций и выполняют функцию библиографической базы.

Библиометрический обзор (англ. bibliometric review) построен на подробном анализе публикаций по какой-либо тематике с точки зрения библиометрических показателей, включая количество цитирований, в том числе во времени, на анализе журналов, в которых опубликованы статьи, вошедшие в обзор, по библиометрическим показателям (квартилям, индексу Хирша или импакт-фактору в зависимости от библиометрической базы), на изучении аффилиаций, организаций и стран авторов. Отбор источников для библиометрического обзора может осуществляться по разным методикам (систематический обзор, теоретический обзор и др.). Главное - библиометрический анализ тех источников, которые отбираются Аля обзора.

Обзор обзоров (англ. review of reviews; umbrella review) представляется сравнительно редким видом обзора. Есть несколько методик его проведения, которые в основном сводятся к применению метаанализа. В медицине значительная часть обзоров занимается анализом данных, полученных в результате различных клинических испытаний и практики. Часть таких обзоров носят произвольный характер, но значительно большее распространение получили систематические обзоры и метаанализ. Естественно, перенос методологии таких обзоров в другие науки, включая социогуманитарные, возможен только при существенной адаптации. Если в так называемой доказательной медицине систематический обзор служит для анализа сходства и различий клинических испытаний по определённой проблематике, в результате чего устанавливаются тенденции, делаются выводы по эффективности методов лечения [4], то в социальных науках в такого рода обзорах обобщается опыт реализации, например, педагогических технологий, социальных практик и пр. Систематические обзоры могут включать результаты исследований, проведённых на разных выборках и разными методами. Поэтому они часто могут быть предвзятыми. Метаанализ в дополнение к тому, что используется в систематическом обзоре, обращается к статистическим методам, осуществляя количественный синтез [4]. Аля проведения метаанализа важна го- 
Общий алгоритм построения научного текста: риторическая схема обзора

A uniform algorithm of scholarly text construct: a rhetoric schema of review

\begin{tabular}{|c|c|}
\hline $\begin{array}{l}\text { Риторические события } \\
\text { Риторические шаги } \\
\text { Rhetoric steps \& moves }\end{array}$ & $\begin{array}{l}\text { Содержание риторического шага } \\
\text { Rhetoric Move Implications }\end{array}$ \\
\hline \multicolumn{2}{|r|}{ Риторическое событие I. Аннотация } \\
\hline Риторический шаг 1.1 & $\begin{array}{l}\text { Введение в тему. Актуальность темы. Желательно обоснование проведения данно- } \\
\text { го обзора (пробел в знании) }\end{array}$ \\
\hline Риторический шаг 1.2 & Описание методологии обзора \\
\hline Риторический шаг 1.3 & $\begin{array}{l}\text { Описание отобранного массива информации. Шаги } 1.2 \text { и } 1.3 \text { могут быть объедине- } \\
\text { ны в одном предложении }\end{array}$ \\
\hline Риторический шаг 1.4 & Результаты обзора - тренды, пробелы, перспективы развития проблематики \\
\hline \multicolumn{2}{|r|}{ Риторическое событие II. ВвеАение } \\
\hline Риторический шаг 2.1 & Актуальность темы обзора \\
\hline Риторический шаг 2.2 & $\begin{array}{l}\text { Описание значимости тематики в науке через анализ публикаций и аналогичных } \\
\text { обзоров }\end{array}$ \\
\hline Риторический шаг 2.3 & $\begin{array}{l}\text { Опираясь на анализ ранее опубликованных аналогичных обзоров, а также публи- } \\
\text { каций по теме за последние годы, дать обоснование необходимости проведения и } \\
\text { публикации данного обзора }\end{array}$ \\
\hline Риторический шаг 2.4 & Цель обзора. Гипотеза исследования. Исследовательские вопросы \\
\hline \multicolumn{2}{|r|}{ Риторическое событие III. Методы } \\
\hline Риторический шаг 3.1 & $\begin{array}{l}\text { Описание алгоритма поиска источников для обзора: какие базы, какие публикации, } \\
\text { за какой период; поисковая стратегия }\end{array}$ \\
\hline Риторический шаг 3.2 & Критерии включения и критерии исключения источников \\
\hline Риторический шаг 3.3 & Процедура проведения исследования (обзора) \\
\hline \multicolumn{2}{|r|}{ Риторическое событие IV. Результаты обзора } \\
\hline Риторический шаг 4.1 & Выявление тенденций исследований в предметной области или тематике \\
\hline Риторический шаг 4.2 & Выявление пробелов в исследованиях в предметной области или тематике \\
\hline Риторический шаг 4.3 & $\begin{array}{l}\text { Анализ тенденций и пробелов. Сопоставление с ранее полученными результатами } \\
\text { (например, в других обзорах) }\end{array}$ \\
\hline Риторический шаг 4.4 & $\begin{array}{l}\text { Ограничения обзора. Перспективы дальнейших исследований (здесь или см. рито- } \\
\text { рический шаг 5.3) }\end{array}$ \\
\hline \multicolumn{2}{|r|}{ Риторическое событие V. Заключение } \\
\hline Риторический шаг 5.1 & Как достигнута цель, поставленная во введении \\
\hline Риторический шаг 5.2 & $\begin{array}{l}\text { Краткое обобщение ответов на исследовательские вопросы (результаты и их } \\
\text { новизна) }\end{array}$ \\
\hline Риторический шаг 5.3 & (По выбору автора) Перспективы дальнейших исследований \\
\hline
\end{tabular}

могенность данных анализируемых исследований и рандомизация при конструировании выборок.

«Scoping Reviews» как новый вид обзоров появились в 2005 г. и представляют собой обзорь предметного поля (или обзоры «охвата» предметного поля). Впервые были разработаны в медицинских науках. Цели такого вида обзоров - определить границы предметного поля, выявить тенденции в ис- следованиях и пробелы в знании [5]. По мнению Х. Аксей и $\Lambda$. О’Мэлли, такие обзоры в доказательной медицине могут предварять систематические обзоры.

\section{Формат и структура обзоров}

Согласно предложенной Ажоном Свейлзом риторической теории научного текста, статья строится как последовательность риторических событий (moves), которые, в 
свою очередь, состоят из риторических шагов (steps) [6]. Примерами таких событий являются крупные структурные части текста - введение, методы, результаты исследования и пр. В свою очередь, риторические шаги дают алгоритм построения риторического события. Например, введение может состоять из следующих шагов: актуальность темы; общий обзор исследований по проблематике; пробел в знании, дающий основание для проведения настоящего исследования; гипотеза и цель исследования; исследовательские вопросы. Задача пишущего - так функционально расположить риторические шаги, чтобы риторическое событие привело к эффективной научной коммуникации.

В таблице 1 представлены традиционные риторические схемы (rhetoric schemas), которые можно применить к обзорам. Следует отметить, что каждый обзор может строиться с некоторыми отступлениями от схемы, если этого потребует логика. Могут вводиться, разумеется, дополнительные события и шаги.

Риторический алгоритм отражает устоявшуюся научную логику текста обзоров, что подтверждается частотой его использования в журналах. Хотя алгоритм создан на основе английских текстов, он может быть в основном перенесён и в русский научный текст. Опора на риторику со стороны международных научных журналов, хотя и не всегда напрямую указывается в требованиях к авторам и статьям, негласно поддерживается и связана с устоявшейся практикой последних 20 лет, когда в научной периодике чётко присутствует жёсткое структурирование статей, позволяющее редакторам, рецензентам и читателям с лёгкостью осуществлять навигацию по методологическим и смысловым компонентам публикаций.

Авторы данной статьи ставят своей целью ответить на следуюшие исследовательские вопросы.

(1) Что представляет собой высокоцитируемый обзор по образованию, опубликованный в международных журналах?
(2) Какие тематические кластеры обзоров наиболее хорошо представлены, в каких аспектах рассматриваются популярные тематики?

(3) Что представляет собой международный высокоцитируемый обзор по высшему образованию с позиции библиометрии и методологии?

\section{Топ-100 самых цитируемых} обзоров по тематике высшего образования (по базе Scopus)

Критерии включения. Учитывая, что в международную наукометрическую базу данных Scopus входит 1351 рецензируемый журнал по образованию (в предметной области «Социальные науки»- «Образование»), большинство из которых публикуют исследования и обзоры по высшему образованию, было решено отобрать и проанализировать 100 самых высокоцитируемых обзоров по проблематике высшего образования за период с 2009 по 2019 гг., проиндексированных в указанной базе. Был введён исходный поисковый запрос «higher education», который был уточнён за счёт следующих критериев включения и критериев исключения (Табл. 2).

В результате поиска было отобрано 7422 обзора по социальным наукам (на 10.11.2019 г.), которые были распределены по количеству полученных цитирований (по убыванию). Несмотря на то, что отбирались источники с 01.01.2009 по 10.11.2019 г., в Топ100 попали обзоры с 2009 по 2017 гг., обзоры за 2018 и 2019 гг. не вошли из-за относительно невысокого количества цитирований.

Контент-анализ отобранных документов привёл к формированию тематических кластеров (групп статей, объединённых общей тематикой). Все 100 обзоров были обозначены нами тематическими маркерами при кодировании. Предварительно маркеры были определены при анализе ключевых слов отобранных обзоров. В ходе контентанализа они уточнялись. Характеристики данного этапа исследования: 
Критерии включения и искдючения источников из обзора

Review inclusion and exclusion criteria

\begin{tabular}{|c|c|c|}
\hline & $\begin{array}{c}\text { Критерий включения в обзор } \\
\text { Inclusion Criteria } \\
\end{array}$ & $\begin{array}{c}\text { Критерий исключения из обзора } \\
\text { Exclusion Criteria } \\
\end{array}$ \\
\hline Поле Аля поиска & $\begin{array}{l}\text { «Higher education» в поле наименования до- } \\
\text { кумента, аннотации и ключевых слов }\end{array}$ & Остальные поля поиска \\
\hline Fields for Search & $\begin{array}{l}\text { 'Higher education' in the field 'Article Title, } \\
\text { Abstract, Keywords' }\end{array}$ & All other fields \\
\hline $\begin{array}{l}\text { Период времени } \\
\text { Period }\end{array}$ & 2009-2019 & $\begin{array}{l}\text { Ранее } 2009 \\
\text { Before } 2009\end{array}$ \\
\hline $\begin{array}{l}\text { Отрасль знаний } \\
\text { Subject Area }\end{array}$ & $\begin{array}{c}\text { Социальные науки } \\
\text { Social sciences }\end{array}$ & $\begin{array}{c}\text { Остальные отрасли } \\
\text { Other areas } \\
\end{array}$ \\
\hline $\begin{array}{l}\text { Tип документа } \\
\text { Document Type }\end{array}$ & $\begin{array}{l}\text { Oбзор } \\
\text { Review } \\
\end{array}$ & $\begin{array}{c}\text { Остальные типы документов } \\
\text { Other types }\end{array}$ \\
\hline $\begin{array}{c}\text { Язык(и) } \\
\text { Language(s) } \\
\end{array}$ & $\begin{array}{l}\text { Английский; русский } \\
\text { English; Russian }\end{array}$ & $\begin{array}{c}\text { Аругие языки } \\
\text { Other languages } \\
\end{array}$ \\
\hline $\begin{array}{l}\text { Tематика } \\
\text { Themes }\end{array}$ & $\begin{array}{l}\text { Высшее образование (все аспекты) } \\
\text { Higher education (all aspects) }\end{array}$ & $\begin{array}{l}\text { Аругая тематика } \\
\text { Other themes }\end{array}$ \\
\hline
\end{tabular}

(1) обзоры, имеющие дробную тематику, были объединены (если не было возможности объединить их в подгруппы в кластере);

(2) введены общие, так называемые «родовые» кластеры по тематике: «высшее образование»; «обучение»; «преподавание»; «оценивание»; «обратная связь»; «технологии»; «инновации»; «студент»;

(3) после кодирования документов авторы сопоставили свои индивидуальные результаты. Согласованность оказалась высокой, что подтверждает рассчитанный показатель коэфффициент каппа Коэна $(\kappa=0.83)$. Распределение публикаций по тематическим кластерам приведено в таблице 3.

\section{Библиометрические характеристики обзоров}

100 обзоров за 10 лет (фактически за восемь), отобранные тематически и по количеству цитирований, включают и публикации, имеющие свыше 100 цитирований $(\mathrm{n}=18)$, и обзоры с цитированием ниже 30. Самая высокоцитируемая публикация (546 цитирований на 10.11.19 г.) - «Key competencies in sustainability: A reference framework for academic program development» [7]. Менее 29 цитирований набрали четыре обзора. Из
100 обзоров четыре не имели аннотаций. Три опубликованы в журнале College and Research Libraries News (это соответствует правилам журнала). Один обзор без аннотации опубликован в ежегоднике AILA Review, где резюме статей также не предусмотрены. Средний размер аннотации $(\mathrm{n}=96)$ составил 178 слов, при этом самая большая аннотация включала 361 слово [8], а самая короткая -68 слов [9].

Расчёт коэффициента корреляции Пирсона для выявления зависимости между возрастом статьи (обзора) в годах и количеством цитирований по всем отобранным обзорам показал, что существует статистически значимая корреляционная связь между параметрами $\mathrm{p} \leq 0,05$ ( $\mathrm{r}_{\text {эмп. }}=0,20512$; $\left.\mathrm{r}_{0.01}=0,25648 ; \mathrm{r}_{0.05}=0,19655\right)$. Это означает, что актуальность тематики и интерес к ней широкой научной общественности вносят некоторый вклад в количество цитирований; возраст статьи влияет на рост цитирований в существенно большей степени.

Отобранные публикации были опубликованы в 67 рецензируемых журналах, из них более чем одна публикация - в 18 журналах. Больше всего высокоцитируемых обзоров вышли на страницах журналов Educational 
Основные тематические кластеры Топ 100

Key topical clusters of Top-100

\begin{tabular}{|c|c|c|}
\hline $\begin{array}{c}\text { Наименование } \\
\text { кластера } \\
\text { Cluster Title }\end{array}$ & $\begin{array}{c}\text { Количество } \\
\text { обзоров } \\
\text { Review Number }\end{array}$ & $\begin{array}{c}\text { Комментарии } \\
\text { Commentary }\end{array}$ \\
\hline $\begin{array}{c}\text { Образовательные } \\
\text { технологии } \\
\text { Educational } \\
\text { Technologies }\end{array}$ & 18 & $\begin{array}{l}\text { К данному кластеру относятся, как образовательные, или педагогиче- } \\
\text { ские (educational, instructional \& learning technologies), так и информа- } \\
\text { ционно-коммуникационные технологии (information and communication } \\
\text { technologies, ICT). Большое внимание уделяется конкретным форматам } \\
\text { внедрения технологий в образовательное пространство, преодолению ба- } \\
\text { рьеров на пути их эффективного использования. }\end{array}$ \\
\hline $\begin{array}{c}\text { Высшее } \\
\text { образование } \\
\text { Higher Education }\end{array}$ & 17 & $\begin{array}{l}\text { Кластер охватывает разную тематику, включая: (1) доступность образо- } \\
\text { вания с точки зрения этноконфессионального, социального, гендерного } \\
\text { факторов, определяющих существование целого ряда социальных иден- } \\
\text { тичностей современных студентов; (2) качество и парадигму знания, про- } \\
\text { дуцируемого в рамках послешкольного и высшего образования; (3) ака- } \\
\text { демическую этику; (4) влияние рейтингования вузов на проводимую ими } \\
\text { политику и экспорт образования; (5) маркетизацию образования. }\end{array}$ \\
\hline $\begin{array}{l}\text { Студенты } \\
\text { Students }\end{array}$ & 12 & $\begin{array}{l}\text { Активно исследуется самоэффективность студентов в образовательной } \\
\text { деятельности, их мотивация к деятельности и навыки, которые необходи- } \\
\text { мы современному студенту для успешной реализации в профессии. Тща- } \\
\text { тельно анализируется проблематика построения эффективного образо- } \\
\text { вательного пространства для студентов с «неравными» образовательны- } \\
\text { ми возможностями (студентов-инвалидов, студентов-ветеранов боевых } \\
\text { действий, студентов с особенностями психического развития, студентов } \\
\text { из числа этноконфессиональных меньшинств и т.д.). }\end{array}$ \\
\hline $\begin{array}{l}\text { Обучение } \\
\text { Learning }\end{array}$ & 11 & $\begin{array}{l}\text { Процесс обучения в рецензиях анализируется с точки зрения формирова- } \\
\text { ния продуктивной образовательной среды, ориентированной на обучаю- } \\
\text { щегося, построенной на базе перевёрнутого урока и проектного обучения } \\
\text { и эффективно направляемой преподавателями, постоянно повышающими } \\
\text { свою квалификацию. Речь идёт о максимально продуктивном повышении } \\
\text { квалификации, трансформирующем портрет современного преподавателя. }\end{array}$ \\
\hline $\begin{array}{c}\text { Оценивание } \\
\text { Assessment }\end{array}$ & 10 & $\begin{array}{l}\text { Оценивание как эффективный инструмент измерения образовательных до- } \\
\text { стижений и механизм формирования идентичности студента анализирует- } \\
\text { ся (1) с позиций правомочности/неправомочности его использования в выс- } \\
\text { шем образовании, (2) с позиций его конкретного воплощения в реальную } \\
\text { образовательную практику. Формирующее и итоговое оценивание, оцени- } \\
\text { вание со стороны преподавателей и со стороны сверстников утверждаются } \\
\text { в качестве действенных алгоритмов современного образования, с акцентом } \\
\text { на их недостаточную изученность и сюрпризы, которые таят в себе их пока } \\
\text { ещё не анонсированные широкой общественности, скрытые возможности. }\end{array}$ \\
\hline $\begin{array}{c}\text { Преподавание } \\
\text { Tеaching }\end{array}$ & 10 & $\begin{array}{l}\text { Рецензии в рамках проблемного поля «преподавание» так или иначе ак- } \\
\text { центируют необходимость перманентного саморазвития преподавателя, } \\
\text { повышения его квалификации, расширения пакета его компетенций за } \\
\text { счёт привлечения знаний о семьях обучающихся, их ближайшем окру- } \\
\text { жении и развития собственной рефлексии. Анализируются механизмы, } \\
\text { лежащие в основе формирования идентичности преподавателя, и факто- } \\
\text { ры, способствующие/препятствующие её развитию. Также фундируется } \\
\text { необходимость соотнесения теоретизированных программ обучения с ре- } \\
\text { альностью и карьерными устремлениями обучающихся, в том числе инте- } \\
\text { грируя преподавание профессионально-ориентированных предметов на } \\
\text { английском языке, расширяя тем самым возможности для дальнейшего } \\
\text { развития студента. }\end{array}$ \\
\hline
\end{tabular}




\begin{tabular}{|c|c|c|}
\hline $\begin{array}{l}\text { Наименование } \\
\text { кластера } \\
\text { Cluster Title }\end{array}$ & $\begin{array}{l}\text { Количество } \\
\text { обзоров } \\
\text { Review Number }\end{array}$ & $\begin{array}{c}\text { Комментарии } \\
\text { Commentary }\end{array}$ \\
\hline $\begin{array}{l}\text { Медицинское } \\
\text { образование и } \\
\text { сестринское дело } \\
\text { Medicine \& } \\
\text { Nursing }\end{array}$ & 7 & $\begin{array}{l}\text { Медицинское образование и сестринское дело анализируются с позиций } \\
\text { необходимости их постоянной оптимизации и унификации на междуна- } \\
\text { родном пространстве. Обсуждаются возможные коллаборации межАу } \\
\text { учебными заведениями подобного профиля с целью развития образова- } \\
\text { тельных программ и компетенций, необходимых для будущих врачей и } \\
\text { медсестёр: по мнению исследователей, необходимо усилить нацеленность } \\
\text { на совместную работу, поскольку эта категория обучающихя склонна } \\
\text { к индивидуальным стратегиям получения знаний. Также анализируются } \\
\text { категории компетенций, вне которых профессиональное развитие врачей } \\
\text { и медсестёр окажется менее продуктивным. }\end{array}$ \\
\hline $\begin{array}{l}\text { Онлайн-обучение } \\
\text { Online education }\end{array}$ & 6 & $\begin{array}{l}\text { Онлайн-обучение рецензируется исходя из формируемой им мотивации } \\
\text { студентов к образовательной деятельности, их удовлетворённости про- } \\
\text { цессом и результатами образовательных активностей. Концепция онлайн- } \\
\text { образования предполагает формирование у студентов саморегулируемых } \\
\text { стратегий обучения. Онлайн-преподаватель как самостоятельная профес- } \\
\text { сия, требующая особой подготовки и постоянного совершенствования, } \\
\text { мыслится в качестве краеугольного камня образовательных прорывов. }\end{array}$ \\
\hline $\begin{array}{c}\text { Выпускники } \\
\text { Graduates }\end{array}$ & 5 & $\begin{array}{l}\text { Проблематика анализируется с двух базовых точек зрения: соответствие } \\
\text { компетенций, формируемых в рамках образовательных программ вузов, } \\
\text { реалиям рынка труда и пробелы в формировании и развитии гибких на- } \\
\text { выков, без которых невозможно полноценное функционирование совре- } \\
\text { менного специалиста. }\end{array}$ \\
\hline $\begin{array}{l}\text { Образование для } \\
\text { устойчивого } \\
\text { развития } \\
\text { Education for } \\
\text { Sustainability }\end{array}$ & 5 & $\begin{array}{l}\text { В статьях данного кластера есть прямое указание на связь с «образова- } \\
\text { нием для устойчивого развития» (education for sustainability; education for } \\
\text { sustainable development) }\end{array}$ \\
\hline $\begin{array}{l}\text { Обратная связь } \\
\text { Feedback }\end{array}$ & 5 & $\begin{array}{l}\text { Обратная связь как универсальный механизм развития образования ис- } \\
\text { следуется с позиции (1) получения обратной связи студентами и их не- } \\
\text { готовности (в ряде случаев) использовать её результаты, (2) оценивания } \\
\text { студентами образовательных программ и деятельности преподавателей. } \\
\text { Исследователи акцентируют плюсы и негативные аспекты оценивания, } \\
\text { находятся в поиске его идеальной модели. }\end{array}$ \\
\hline $\begin{array}{c}\text { Инновации } \\
\text { в образовании } \\
\text { Innovations } \\
\text { in education }\end{array}$ & 4 & $\begin{array}{l}\text { Инновации в образовании рассматриваются как необходимый элемент } \\
\text { его развития, в том числе и в нестандартных направлениях (например, } \\
\text { введение медитаций в образовательное пространство). Вместе с тем, вне- } \\
\text { дрение инноваций должно быть обоснованным и своевременным и не за- } \\
\text { висеть от политической конъюнктуры. Значительный интерес вызывает } \\
\text { появление научных центров, аккумулирующих образование, бизнес и } \\
\text { производство. Анализируется специфика и обоснованность функциони- } \\
\text { рования подобных центров. }\end{array}$ \\
\hline $\begin{array}{l}\text { Научные и } \\
\text { университетские } \\
\text { библиотеки } \\
\text { Scientific and } \\
\text { University libraries }\end{array}$ & 3 & $\begin{array}{l}\text { Научные и университетские библиотеки в новом прочтении должны пре- } \\
\text { вратиться в центры обработки и хранения информации в соответствии с } \\
\text { новыми стандартами представления информации. Необходимым аспек- } \\
\text { том их работы должны являться консультативные услуги по обработке и } \\
\text { систематизации информации. }\end{array}$ \\
\hline $\begin{array}{c}\text { Систематические } \\
\text { обзоры в высшем } \\
\text { образовании } \\
\text { Systematic reviews }\end{array}$ & 2 & $\begin{array}{l}\text { Систематические обзоры в высшем образовании рассматриваются как ис- } \\
\text { точник сжатого представления информации, использование которой для } \\
\text { развития высшего образования способно привнести новые горизонты. }\end{array}$ \\
\hline
\end{tabular}


Research Review (8) и Assessment and Evaluation in Higher Education (5). Издания, где были опубликованы отобранные обзоры, распределяются по квартилям следующим образом: Q1 - 50; Q2 - 12; Q3 - 4; Q4 - нет публикаций.

Одна публикация (2011 г.) вышла в журнале Journal of Asynchronous Learning, индексация которого в Scopus прекращена в 2016 г. 10 обзоров вышли в журналах, которые не относятся к отрасли знания «Образование». Все отобранные статьи относятся к «Социальным наукам», при этом по шесть к «Бизнесу, менеджменту и бухучёту» и «Компьютерной науке»; к «Гуманитарным наукам» - 5; «Экологическим наукам» - 5; «Сестринскому делу» - 4; «Психологии»3 ; «Инженерному делу» - 3; «Химии»- 2; «Медицине» - 2; «Энергетике» и «Фармакологии» - по 1 публикации соответственно.

72 обзора опубликованы в журналах, принадлежащих самым крупным издательствам научной литературы в мире: Taylor \& Francis - 22; Elsevier - 15; Springer Nature 14; SAGE - 10; Emerald Publishing - 7; WileyBlackwell - 4. Основная часть публикаций приходится на авторов с аффилиацией в университетах и научных центрах следующих стран: США (30); Великобритания (15); Австралия (14); Канада (10); Нидерланды (8); Бельгия (6). Всего представлены 23 страны. Российских учёных по аффилиации и национальной принадлежности среди авторов нет. Среди университетов лидируют (по три публикации каждый): Университет Пердью (США), Университет Антверпена (Бельгия), Университет Флориды (США), Университет Тасмании (Австралия), Университет Торонто (Канада), Маастрихтский университет (Нидерланды), Кёвенский католический университет (Бельгия), Калифорнийский университет (США). Авторами обзоров являются учёные из 134 университетов и научных центров. Среднее количество авторов на одну публикацию в Топ-100 составило 1,64.

Технологии в образовании. Проблематика технологий в образовании стала пред- метом анализа 18 топовых обзоров с безусловной пальмой первенства (10 статей) у информационных технологий. Также активно анализируются модификации учебных занятий (перевёрнутый класс, занятия с опорой на мобильные девайсы). Несмотря на существование значительного числа исследований в данном предметном поле, авторы отмечают, что выводы о воздействии технологий Web 2.0 на процесс обучения учащихся пока ещё недостаточно аргументированы [10; 11] ввиду преобладания эмпирических исследований, опирающихся на самооценку учащимися учебного процесса с использованием Web 2.0 (анализ их анкет и интервью). Вместе с тем ни в одном из исследований не фиксируется негативного воздействия интернет-опосредованных и компьютерных технологий на процесс обучения и образовательные результаты. Положительный эффект от их использования исследователи связывают скорее не с самими технологиями как таковыми, а с тем, как они используются в образовательном процессе. Наиболее позитивные результаты демонстрирует педагогика сотрудничества, проектное обучение с опорой на блоги [12], вики-платформы и открытые образовательные ресурсы [13], подкасты. В то же время, например, педагогические возможности социальных сетей реализованы лишь частично [7], и, соответственно, эффективность их использования страдает.

В обзорах отчётливо прослеживается тенденция к выявлению тех аспектов педагогических интернет-технологий, которые формируют мотивацию обучающихся и определяют их удовлетворённость учебным курсом [14]. В широком смысле намечается тенденция восприятия технологий вебпространства в качестве своего рода социального программного обеспечения, позволяющего получать неотсроченную обратную связь и сплачивающего обучающихся [15]. Акцентируется мысль о необходимости управления процессом распространения и внедрения технологий в учебный процесс в 
высшем учебном заведении [16] с целью планомерного и обоснованного преодоления барьеров на пути их эффективной интеграции в образовательный ландшафт [17]. Число публикаций, посвящённых этой теме, растёт в геометрической прогрессии (в среднем увеличивается в четыре раза в течение пяти лет) [18]. Вместе с тем исследователи глубоко анализируют предположения и убеждения, лежащие в основе исследований в области образовательных технологий, ведь недостаточно изученные допущения зачастую приводят к сомнительным выводам [11] и неочевидным образовательным результатам.

Высшее образование. Высшее образование оказалось в фокусе 17 статей из нашей выборки, четыре представляют собой обзоры публикаций по экономике образования. В своём обзоре К. Аинч проводит мысль о том, что культура высшего образования определяется не только управленческими ценностями и нормами. По мнению исследователя, высшее образование характеризуется позицией «безмятежности» («беспристрастности»), имеющей историческую традицию. Проблемы современной культуры высшего образования коренятся в классической картезианской трактовке научного образования, согласно которой (1) научная работа и эмоции / чувства полярны, а в центре внимания образования должно находиться воспитание автономной и рациональной личности; (2) факт должен быть отделён от ценности [19].

Активно осуществляется анализ неравенства возможностей получения высшего образования (вследствие этноконфессионального, гендерного, социального факторов или изменяющихся социальных / личностных идентичностей), который сохраняется, несмотря на усилия, предпринимаемые на государственном уровне [20]. Согласно представленным данным, социальное происхождение студентов существенным образом влияет на выбор специализации их обучения. Так, в Германии диапазон специальностей Аля обучения в вузе студентов из различных социальных слоёв практически не изменя- ется, равно как не меняются используемые ими образовательные стратегии, несмотря на продолжающуюся политику расширения доступности среднего и высшего образования со стороны государства [21]. В фокус попали и исследования относительно влияния «мозаичности» современных образовательных социумов на образовательные результаты их членов. Несмотря на зафиксированный в целом положительный эффект соприкосновения различных идентичностей в рамках образовательного взаимодействия, отмечается необходимость создания психологических и социальных механизмов, способных существенным образом повысить качество и результативность такого взаимодействия [22].

В центре внимания оказалась и проблематика платного обучения. Так, в своём обзоре на основе анализа ситуации в американских колледжах с 1991 по 2006 гг. С. Хемелт и А. Маркот приводят данные, согласно которым увеличение стоимости обучения на 100 долларов приводит к снижению числа поступающих примерно на $0,25 \%$, что увеличивает барьеры к получению послешкольного образования [23]. Качество образования и его монетизация зачастую анализируются в совокупности. Исследователи призывают потенциальных студентов тщательно проанализировать свои ожидания от будущей профессии и связанных с нею заработков, с тем чтобы плата за образование оказалась адекватной этим ожиданиям. Подобный подход позволит корректно определить собственные образовательные стратегии (колледж, вуз, курсы) и сохранит психологическое благополучие студентов [24].

Заслуживают интереса обзоры, исследующие общемировую борьбу университетов за места в международных рейтингах. В своём исследовании о ситуации в Гонконге К. Мок и А. Ченг анализируют основные направления политики и стратегии, применяемые правительством и университетами в стремлении к получению статуса университета мирового класса. Это стремление порождает политику конкуренции между 
учебными заведениями как за государственные, так и за негосударственные ресурсы Аля привлечения и удержания талантливых студентов и с целью интернационализации их учебных программ для развития экспорта образования. Отмечается возникновение напряжённости между необходимостью поддержания качества преподавания и масштабных исследований, между статусами различных учебных дисциплин в образовательных программах университетов [25].

Интересной областью исследования представляется трансдисциплинарность знания, производимого университетами. Трансдисциплинарность рассматривается в качестве универсального механизма, призванного способствовать решению глобальных проблем современности. Согласно обзору А. Бернштейна, она должна базироваться на творческом подходе к продуцированию креативных решений, с опорой на вовлечённость заинтересованных сторон и социально ответственную науку. Позволяя одновременно изучать множество уровней и углов зрения на решаемую проблему, такой подход обеспечивает потенциал для активизации научных исследований как в вузах, так и за их пределами [26]. Весьма актуальной в этой связи становится и проблематика академической добросовестности, исследующей ценности, нормы и поведение преподавателей вузов во всех ипостасях своей деятельности. В обзоре исследований западных и китайских учёных, изучающих академическую честность и неподкупность, Б. Макфарлайн, Аж. Жанг и А. Пан с сожалением констатируют достаточно частые случаи ненадлежащего поведения или академической коррупции, при этом доминирующее место в рейтинге антиакадемических проявлений занимает исследовательская этика [27].

Образование для устойчивого развитил. В мировом образовательном дискурсе выражение «образование для устойчивого развития» (ОУР) становится популярным с 2015 г., когда на смену Целям тысячелетия ООН (2000 г.) пришли Цели устойчивого развития (ЦУР), включившие в себя 17 областей. Цель 4 «Образование для устойчивого развития» с разной степенью активности реализуется в большинстве стран мира, что должно к 2030 г. привести к формированию у обучающихся на всех уровнях образования «знаний и навыков, необходимых для содействия устойчивому развитию».

В отобранных обзорах ОУР посвящено пять публикаций, при этом первое место по цитированию среди самых цитируемых обзоров занял именно обзор по тематике ОУР. В публикации [6] сделан вывод о том, что в силу расплывчатости определений и неоднозначности терминологии ключевые компетенции для устойчивого развития имеют разные таксономии. Обзор основан на статьях из рецензируемых журналов, материалах «серой» литературы (то есть докладах, рабочих документ с нею связанных и пр.) и опубликованных учебных программах и учебных планах. Была составлена обширная компиляция компетенций, выделены следующие ключевые компетенции: компетенция системного мышления, прогностическая компетенция, нормативная компетенция, компетенция стратегического мышления и компетенция межличностного общения.

Остальные обзоры по ОУР включают: анализ реализации концепции УР в учебных программах канадских университетов [28] на основе системы оценки из 10 кластеров и 56 показателей, которая позволяет унифицировать полученные результаты; критический обзор вызовов, связанных с УР, в котором сделан вывод о необходимости радикальных трансформаций обучения и внедрении преобразующего обучения (англ. transformative/ transgressive learning), привоАящего к пересмотру ценностей и смыслов, изменению образа жизни и расширению сознания; обзор теоретических, методологических и практических оснований ОУР, различий в практиках внедрения в учебные программы; обзор публикаций в восьми ведущих научных рецензируемых журналах по проблематике УР и ОУР с точки зрения 
выделения наиболее значимых тенденций в исследованиях; сопоставление политики различных кампусов, методологий аудита и оценки результатов внедрения концепции УР в учреждениях постсреднего образования [29].

Медииинское образование и сестринское дело. Медицинское образование нуждается в усовершенствовании на всех его уровнях, как с точки зрения его процессуальной реализации, так и с точки зрения его доступности для всех категорий студентов. Новая модель медицинского образования, основанная на компетентности преподающих и обучаемых и ориентированная на обучающихся, сможет полнее удовлетворять потребности системы здравоохранения. К числу необходимых инноваций относят сотрудничество между медицинскими учебными заведениями с целью разработки массовых открытых онлайн-курсов с опорой на дидактический контент; работу преподавателей в небольших группах с целью использования вышеуказанного онлайнового контента в перевёрнутой модели урока; а также цифровые бейджи для отслеживания качества деятельности студента на протяжении всего процесса обучения [30].

Европейское пространство высшего образования нацелено на обеспечение сопоставимых, совместимых и целостных систем высшего образования в области медицинского образования и сестринского дела, что требует согласованных действий всех стран в этой области [31]. Улучшение качества сестринского образования и унификация требований к квалификации сестёр требуют пристального внимания. Перечень ключевых категорий квалификационных требований к медсёстрам был сформулирован в обзоре К. Сату и др.: (1) профессиональные и этические ценности, (2) навыки сестринского дела, (3) коммуникативные и межличностные навыки, (4) знания и когнитивные способности, (5) стремление к улучшению качества сестринского дела и умение его оценивать, (6) профессиональное развитие, (7) лидерство, управление и умение работать в команде, (8) умение использовать результаты современных исследований в деятельности [32]. Хотя будущие медицинские сёстры изучают сбалансированную учебную программу, они, согласно проведённым исследованиям, не считают себя вовлечёнными в студентоцентрированную парадигму обучения. Соответственно, привнесение активных коллаборативных стратегий в образовательное пространство способно качественным образом улучшить набор компетенций, необходимых для эффективной реализации сестринского дела [33].

Студенты. Борьба университетов за высокие позиции в рейтингах и активное участие в экспорте образования актуализируют необходимость активной апробации различных аккультурационных моделей для студентов-иностранцев. Речь идёт не о схоластическом подходе к проблеме, а о детальном социально-психологическом сопровождении этого процесса. Современные образовательные коллективы уже невозможно мыслить в качестве монокультурных, что настоятельно требует отказа от терминологии «терпимости к иному» и формирования атмосферы готовности к подлинному взаимодействию различных социокультурных идентичностей современного студенчества [34]. Университетам необходимо изучать опыт по оказанию поддержки тем слушателям с неравными возможностями, которые сумели поступить в высшие учебные заведения, и совершенствовать собственную институциональную практику в этой области [35].

Значительное внимание уделяется самоэффективности и мотивации студентов в рамках образовательного взаимодействия: именно учёт потребностей и убеждений студентов позволяет образовательным программам стать максимально эффективными [36]. Вызывает интерес исследователей и проблема выстраивания образовательных маршрутов, реализуемых в отношении значимых для развития государства групп населения. Так, образование спортсменов из 
государств - членов Европейского союза требует тщательного подхода, с тем чтобы образовательные интересы этой категории населения не оказались ущемлёнными вследствие их активной спортивной деятельности. К числу основных политических инициатив в университетском секторе, призванных защитить интересы спортсменов, относятся: адаптация академических услуг под график и потребности спортсменов, подготовка к послеатлетической карьере, психологическое сопровождение образовательных траекторий спортсменов [37]. Образование для военных ветеранов также сопряжено с демонстрацией последними непропорционально высокого уровня рискованного поведения, неблагоприятных психологических симптомов, а также трудностей личной и образовательной адаптации, что требует разработки особых подходов к выстраиванию образовательной интеракции [38].

В настоящее время противозаконным является взаимодействие со студентами с ограниченными возможностями в формате их восприятия в качестве лиц, чьи права и возможности ущемлены. Они должны ощущать себя людьми с равными возможностями. Однако исследования выявили многочисленные барьеры, с которыми сталкиваются студенты с ограниченными возможностями, когда пытаются получить доступ к учебной программе высшего образования. Студенты с ограниченными возможностями вынуждены работать значительно усерднее, чтобы преодолеть широкий спектр физических, мировоззренческих, социальных, культурных и политических барьеров. Эта категория студентов зачастую выбирает путь наименьшего сопротивления, предпочитая образование в тех сферах, где этих барьеров окажется меньше. При этом у них остаётся ощущение, что таким образом они подвергаются дискриминации. Необходимо подробно изучать феноменологический мир подобных студентов, с тем чтобы максимально адаптировать политику и практи- ку высшего образования под их реальные возможности [39]. Широкое распространение в современных исследованиях получила проблематика включения студентов с дислексией в образовательный процесс. В центре внимания - стратегии взаимодействия этой категории студентов с преподавательским составом, доступность и адаптация образования, использование ассистивных, информационных и коммуникационных технологий в их обучении [40].

Обучение. Тематическое поле «Обучение» в нашем исследовании представлено 11 обзорами. Рефреном через все обзоры проходит призыв к формированию учебной среды, ориентированной на обучающегося, что подразумевает учёт и выявление поощряющих и дестимулирующих факторов учебной среды, анализ восприятия студентами этого контекста, равно как и личностных характеристик обучающихся. Согласно обзору М. Баетен, И. Кундт, К. Струвен и Ф.Аочи, студенты, изучающие дисциплины различных циклов, по-разному подходят к обучению. Так, «гуманитарии» демонстрируют более глубинный подход. Кроме того, степень вовлечённости преподавателя в процесс обучения и благоприятные контекстуальные факторы значительно повышают степень удовлетворённости студентами качеством курса и их мотивацию к образовательной деятельности [41]. Важными элементами этой среды мыслятся «перевёрнутое обучение» (flipped classroom) и «проблемно-ориентированное обучение» как механизмы включения учебной коммуникации в учебные аудитории [42]. Вторым важным фактором активной образовательной среды является постоянное повышение квалификации педагогов, целью которого является изменение практики работы преподавателей как инструмента оказания позитивного влияния на обучение студентов. Важно понимать, какие практики приводят к каким последствиям. Всё это нуждается в тщательном и продуманном встраивании в рабочую реальность педагога высшей школы [43]. 
Онлайн-обучение. Исследования в области онлайн-обучения в высшем образовании преимущественно сосредоточены на изучении мотивации студентов и их удовлетворённости условиями обучения с использованием Интернета. Анализ показывает, что технологические атрибуты программ и площадок, качество курса, вовлечённость, формат программы и неотсроченная поддержка пользователей формируют мотивацию и удовлетворённость студентов реализуемой ими деятельностью [14]. Онлайн-обучение способствует появлению саморегулируемых стратегий обучения для достижения академических успехов в интернет-среде. Аж. Бродбент и В. Пун выделяют стратегии управления временем, метакогнитивные навыки, умения координировать усилия, критическое мышление, которые маркируются как положительно коррелируемые с академическими результатами [44]. Вместе с тем растёт и роль профессии «онлайн-преподаватель»: в условиях усложнения технологий онлайн-преподавания перенесение практик аудиторного обучения на интернет-преподавание мыслится ошибочным. Предлагается альтернатива, в соответствии с которой онлайн-преподаватели рассматриваются как «перманентные студенты», которые постоянно трансформируют структуры, связанные с онлайновым обучением, посредством непрерывного процесса критического осмысления и практических действий [45].

Оценивание. Различные аспекты оценивания как предмет исследования получили разностороннее освещение в десяти обзоpax. Активно исследуется и проблематика получения студентами адекватной обратной связи, и оценки выполненных заданий в ходе образовательного взаимодействия как инструмента интенсификации и углубления полученных знаний [46]. Интересно, что, приветствуя оценку преподавателя (в том числе и в онлайн-формате), студенты с высокой долей негативности воспринимают оценивание собственных результатов со стороны одногруппников-сверстников, полагая их оценки недостаточно квалифицированными. Аанный подход свидетельствует о характере восприятия степени полезности и позитивности обратной связи со стороны сверстников [47].

Анализируя подходы к формирующему оцениванию, его целям и влиянию на образовательные результаты, исследователи отмечают парадоксальную ситуацию, сложившуюся в современном высшем образовании: формируя креативную, автономную и самобытную личность как продукт образовательных усилий, преподаватель использует оценивание как инструмент соответствия измеряемой дичности неким стандартам. Аанный фокус требует глубинного пересмотра формирующего оценивания, его функций и форм [48]. Аискутируется также влияние внешней коллегиальной оценки студента и его самооценки, их влияние на формирование его идентичности [49]. Интересные данные представлены в обзоре Г. Ажохина, оспаривающие тезис о том, что итоговая оценка максимально стимулирует обучение [50]. Тщательный анализ эмпирических исследований, проведённый авторами, свидетельствует о необходимости пересмотреть данную аксиому, поскольку результаты исследований представляются зачастую в усечённом виде, что приводит к искажённой интерпретации сложных многогранных явлений. Параллельно есть исследования, предлагающие исключить итоговую оценку из образовательного инструментария. Последние недооценивают роль итоговой оценки, что ведёт к риску преувеличения возможностей «альтернативных» форм оценки для содействия эффективности процесса обучения [50]. Все обзоры рекомендуют проведение масштабных исследований с целью выявления преимуществ и недостатков формирующего и итогового оценивания в его различных формах, с тем чтобы прийти к окончательному пониманию их функционала.

Преподавание. Преподавание как объект целенаправленного анализа стало пред- 
метом 10 исследований-обзоров. В них обосновывается мысль, согласно которой современный вуз представляет собой среду, постоянно продуцирующую вызовы для преподавателя. Соответственно, термин «непрерывное академическое развитие» призван стать лозунгом каждого преподавателя вуза. Обзоры свидетельствуют, что личностному развитию преподавателя, укреплению его идентичности способствуют контакты со студентами и программы повышения квалификации; более широкий контекст высшего образования рассматривается в качестве сдерживающего фактора. Воздействие непосредственной рабочей среды либо усиливает, либо ограничивает развитие его идентичности в зависимости от того, насколько ценится его преподавание. Установлено, что в развитии личности учителя участвуют пять психологических процессов: чувство признательности, чувство связи, чувство компетентности, чувство ответственности, воображение буАущей карьерной траектории [51]. Одним из действенных инструментов подобного развития являются стипендии для преподавателей, функциональное использование которых способно сформировать у них полезный навык критической рефлексии [52]. Всё активнее дискутируется вопрос о необходимости целенаправленно формировать у преподавателей качества, позволяющим интегрировать в свою практику взаимодействие с семьями студентов, их ближайшим окружением. Аанная практика, по мнению исследователей, позволит развивать новые педагогические подходы, которые повышают уверенность преподавателей в себе, укрепляют их самооценку, позволяют использовать знания о семьях в целях совершенствования преподавания [53].

В фокусе исследований находится и проблематика, бросающая вызов качеству преподавания: несоответствие между учебными программами, карьерными ожиданиями студентов и реалиями профессиональной практики. На примере исследований ситуа- ции в музыкальном образовании учёные акцентируют необходимость согласования реальной практики с теоретическими образовательными построениями, ориентацию студентов на образование в течение всей жизни [54]. На этом фоне особое звучание приобретает ставшая в последние годы популярной практика оценивания студентами манеры взаимодействия преподавателя с учебной аудиторией, глубины его знаний преподаваемого предмета и умения использовать в своей деятельности разнообразные технологии. Она вызывает в педагогическом сообществе противоречивое отношение: от абсолютного одобрения до полного неприятия. Аанная проблематика остаётся актуальной и в то же время деликатной: есть результаты исследований, свидетельствующие об отсутствии обоснованности такого подхода как для формирующего, так и для итогового оценивания [55].

Приветствуется преподавание, реализуемое на иностранном языке (language integrated learning) как новый вариант расширения горизонта обучающихся без существенных дополнительных энергозатрат. Параллельное изучение контента профильного предмета и английского языка формирует новые практики восприятия и транслирования информации, снижает «страх перед неизведанным» [56].

Обратная связь. Обратная связь имеет огромный образовательный потенциал, давая обучающимся возможность неотложенной корректировки имеющихся пробелов в формируемых компетенциях. Вместе с тем студенты зачастую не пользуются такой возможностью, что связано в большинстве случаев с непониманием академического дискурса [57]. К. Габелика, П. ван ден Бош, М. Сегерс, В. Гийселарс в своём обзоре проанализировали 28 факторов, обеспечивающие эффективную обратную связь [58].

Вузы всё активнее инициируют опросы Аля получения обратной связи от обучающихся по поводу восприятия ими образовательного процесса и преподавательского 
состава. При этом, хотя отзывы студентов ценятся и используются, практика такого рода обследований является идиосинкратической. В большинстве случаев анкеты лишены достоверности и надёжности, данные используются неадекватно, обладают ограниченным потенциалом для межотраслевого сопоставительного анализа, что актуализирует необходимость объективизации подобных механизмов с целью повышения их реальной результативности [59].

Выпускники университета. Семь обзоров из выборки посвящены тематике «Выпускники университета». В рамках данного предметного поля анализируется способность вузовского образования соответствовать изменениям на рынке труда с точки зрения перспективы трудоустройства выпускников [60]. Исследования призывают к реформированию учебных программ и ставят вопрос об ответственности вуза за качество подготовки выпускников к работе в реальном мире. Практически во всех обзорах по проблемам адаптации выпускников вузов к профессиональным реалиям акцентируется необходимость развития гибких навыков [61]. Проблема профессиональной специализации нашла интересное преломление в обзоре М. Персона, анализирующего вопрос о влиянии высшего образования на вовлечённость выпускников вузов в политическую жизнь страны. Автор комментирует две позиции: (1) высшее образование может стать непосредственным активатором политической активности, (2) оно может лишь косвенно влиять на другие факторы (социализация, трансформация социального статуса), способствующие политизации мышления [62].

Научные и университетские библиотеки. Библиотеки вузов представляют собой пространство, аккумулирующее знания и компетенции. В своём исследовании $\Lambda$. Конвей и его коллеги выделяют признаки эффективных академических библиотек. Среди них: (1) ценность для академического сообщества, влияние на востребованность выпускников, развитие их личностных и профессиональных качеств, (2) способность демонстрировать методы эффективной обработки данных, аккумулируя репозитарии и имея в своём арсенале специалистов, которые помогают заинтересованным лицам в поиске и систематизации информации, (3) предъявление архитектуры, политики или стандартов для создания, обеспечения доступа и сохранения цифрового контента, (4) благодаря огромным фондам способность «овеществлять» знание, создавать ощущение уверенности и надёжности в ситуации роста числа онлайновых программ обучения, глобальной обновляемости информации, роста скептицизма в отношении «возврата инвестиций», вложенных в получение высшего образования, (5) адаптация мобильных устройств для доступа к информации в библиотеках, (6) лицензирование использования в библиотеках электронных книг, (7) популяризация научного контента в качестве пространства коммуникации учёных путём презентации новых моделей публикации информации (открытый доступ, подписки на недоступные обычным пользователям источники информации и Aр.) [63].

Инновации. Инновации всегда притягательны, поскольку позволяют расширять привычные горизонты. Вместе с тем А. Кезар в своём обзоре призывает лидеров образования не позволять политикам бездумно вводить инновации в сферу образования. Все нововведения должны быть обусловлены логикой развития образования в каждой стране и способствовать реализации образовательных целей, а не служить инструментом легитимации власти [64].

К числу последних инноваций в сфере высшего образования относят возникновение и развитие центров (хабов) образования, которые вкдючают в себя «местных» и зарубежных студентов (учебные заведения, компании, научно-технические центры). Взаимодействуя, а в некоторых 
случаях и объединяясь, они участвуют в инициативах в области образования, профессиональной подготовки, производства знаний и инноваций. Такие центры создают страны, претендующие на роль центров образования. Аанная идея достаточно нова, что открывает простор для многочисленных исследований - от изучения потенциала подобных центров, их классификации и принципов функционирования до размышлений о том, являются ли они причудой, брендом или инновацией, заслуживающей серьёзного внимания и инвестиций [65].

Систематические обзоры в высшем образовании. В рамках этого предметного поля рассматривается методология систематических обзоров и возможности их применения Аля улучшения высшего образования [66].

\section{Заключение}

Обзоры с их многообразием форм и методик составления имеют широкие перспективы в области педагогики и образования, так как предоставляют учёным объективно отобранные и наиболее значимые труды. Наше исследование показало, что самыми популярными по количеству цитирований и количеству публикаций стали обзоры, посвящённые культуре высшего образования, педагогическим технологиям и особенностям их применения в новом образовательном ландшафте, онлайн-образованию как новому измерению образования, требующему формирования особой экосистемы, академической этике преподавателей вузов, формированию компетенций, необходимых им для успешного профессионального развития, академическим и научным библиотекам как новым центрам коммуникации.

Предложенная авторами данной статьи риторическая схема обзора может стать методологической основой для исследований (обзоров) российских авторов по проблематике в области как высшего образования, так и социально-гуманитарного знания в целом.

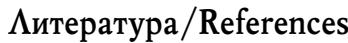

1. Gregory, A.T. \& Denniss, A.R. (2018). An Introduction to Writing Narrative and Systematic Reviews - Tasks, Tips and Traps for Aspiring Authors. Heart, Lungs and Circulation. No. 27, pp. 893-898. DOI: http://doi.org/10.1016/j. hlc.2018.03.027

2. Grant, M.\& Booth, A. (2009). A Typology of Reviews: An Analysis of 14 Review Types and Associated Methodologies. Health Information and Libraries Journal. Vol. 26, no. 2, pp. 91-108. DOI: https://doi.org/10.1111/j.1471-1842.2009.00848

3. Pare, G., Trudel, M.-C., Jaana, M., Kitsiou, S. (2015). Synthesizing Information Systems Knowledge: A Typology of Literature Reviews. Information \& Management. No. 52, pp. 183199. DOI: http://dx.doi.org/10.1016/j.im.2014. 08.008

4. Biondi-Zoccai, G. (2016). Umbrella Reviews: Evidence Synthesis with Overviews of Reviews and Meta-Epidemiologic Studies. Springer. 391 p. DOI: $10.1007 / 978-3-319-25655-9$

5. Arksey,H.\& O'Malley,L.(2005).Scoping Studies: Towards a Methodological Framework. International Journal of Social Research Methodology: Theory and Practice. Vol. 8, no. 1, pp. 19-32.DOI: https://doi.org/10.1080/1364557032000119616

6. Swales, J. (1990). Genre Analysis: English in Academic and Research Settings. Cambridge University Press, $274 \mathrm{p}$.

7. Wiek, A., Withycombe, L., Redman, C.L. (2011). Key Competencies in Sustainability: A Reference Framework for Academic Program Development. Sustainability Science. Vol. 6, no. 2, pp. 203-218. DOI: http://doi.org/10.1007/s11625011-0132-6

8. Manca, S., Ranieri, M. (2016). Is Facebook Still a Suitable Technology-Enhanced Learning Environment? An Updated Critical Review of the Literature from 2012 to 2015. Journal of Computer Assisted Learning. Vol. 32, no. 6, pp. 503-528. DOI: http://doi.org/10.1111/jcal.12154

9. Andraos, J., Dicks, A.P. (2012). Green Chemistry Teaching in Higher Education: A Review of Effective Practices. Chemistry Education Research and Practice. Vol. 13, no. 2, pp. 69-79. DOI: http://doi.org/10.10 39/c1rp90065j

10. Hew, K.F., Cheung, W.S. (2013). Use of Web 2.0 Technologies in K-12 and Higher Education: The Search for Evidence-Based Practice. Educational Research Review. No. 9, pp. 47-64. DOI: http://doi.org/10.1016/j.edurev.2012.08.001 
11. Kirkwood, A., Price, L. (2013). Examining Some Assumptions and Limitations of Research on the Effects of Emerging Technologies for Teaching and Learning in Higher Education. British Journal of Educational Technology. Vol. 44, no. 4, pp. 536-543. DOI: http://doi.org/10.1111/bjet.12049

12. Sim, J.W.S., Hew, K.F. (2010). The Use of Weblogs in Higher Education Settings: A Review of Empirical Research. Educational Research Review. Vol. 5, no. 2, pp. 151-163. DOI: http:// dx.doi.org/10.1016/j.edurev.2010.01.001

13. Knox, J. (2013). Five Critiques of the Open Educational Resources Movement. Teaching in Higher Education. Vol. 18, no. 8, pp. 821-832. DOI: http://doi.org/10.1080/13562517.2013.774354

14. Bekele, T.A. (2010). Motivation and Satisfaction in Internet-Supported Learning Environments: A Review. Educational Technology and Society. Vol. 13, no. 2, pp. 116-127.

15. Thoms, B. (2011). A Dynamic Social Feedback System to Support Learning and Social Interaction in Higher Education. IEEE Transactions on Learning Technologies. Vol. 4, no. 4, pp. 340352. DOI: http://doi.org/10.1109/TLT.2011.9

16. Abrahams, D.A. (2010). Technology Adoption in Higher Education: A Framework for Identifying and Prioritising Issues and Barriers to Adoption of Instructional Technology. Journal of Applied Research in Higher Education. Vol. 2, no. 2, pp. 34-49. DOI: http://doi. org/10.1108/17581184201000012

17. Reid, P. (2014). Categories for Barriers to Adoption of Instructional Technologies. Education and Information Technologies. Vol. 19, no. 2, pp. 383-407. DOI: 10.1007/s10639-012-9222-z

18. Hwang, G., Tsai, C. (2011). Research Trends in Mobile and Ubiquitous Learning: A Review of Publications in Selected Journals from 2001 to 2010. British Journal of Educational Technology. Vol. 42, no. 4, pp. E65-E70.DOI: http://doi. org/10.1111/j.1467-8535.2011.01183.x

19. Lynch, K. (2010). Carelessness: A Hidden Doxa of Higher Education. Arts and Humanities in Higher Education. Vol. 9, no. 1, pp. 54-67. DOI: http://doi.org/10.1177/1474022209350104

20. Rubin, M., Denson, N., Kilpatrick, S., Matthews, K.E., Stehlik, T., Zyngier, D. (2014). "I Am Working-Class": Subjective Self-Definition as a Missing Measure of Social Class and Socioeconomic Status in Higher Education Research. Educational Researcher. Vol. 43, no. 4, pp. 196-200. DOI: http://doi.org/10.3102/0013189X14528373
21. Reimer, D., Pollak, R. (2010). Educational Expansion and Its Consequences for Vertical and Horizontal Inequalities in Access to Higher Education in West Germany. European Sociological Review. Vol. 26, no.4, pp. 415-430. DOI: http:// doi.org/10.1093/esr/jcp029

22. Bowman, N.A., Brandenberger, J.W. (2012). Experiencing the Unexpected: Toward a Model of College Diversity Experiences and Attitude Change. Review of Higher Education. Vol. 35, no. 2, pp. 179-205.DOI: http://doi.org/10.1353/ rhe. 2012.0016

23. Hemelt, S.W., Marcotte, D.E. (2011). The Impact of Tuition Increases on Enrollment at Public Colleges and Universities. Educational Evaluation and Policy Analysis. Vol. 33, no. 4, pp. 435457. DOI: http://doi.org/10.3102/0162373711 415261

24. Oreopoulos, P., Petronijevic, U. (2013). Making College Worth It: A Review of the Returns to Higher Education. Future of Children. Vol. 23, no. 1, pp. 41-65. DOI: http://doi.org/10.1353/ foc. 2013.0001

25. Mok, K.H., Cheung, A.B.L. (2011). Global Aspirations and Strategising for World-Class Status: New Form of Politics in Higher Education Governance in Hong Kong. Journal of Higher Education Policy and Management. Vol. 33, no. 3, pp. 231-251. DOI: http://doi.org/10.1080/1360 080X.2011.564998

26. Bernstein, J.H. (2015). Transdisciplinarity: A Review of Its Origins, Development, and Current Issues. Journal of Research Practice. Vol. 11, no. 1. Article R1. Available at: http://jrp.icaap.org/ index.php/jrp/article/view/510/436

27. Macfarlane, B., Zhang, J., Pun, A. (2014). Academic Integrity: A Review of the Literature. Studies in Higher Education. Vol. 39, no. 2, pp. 339-358. DOI: http://doi.org/10.1080/0307507 9.2012.709495

28. Fonseca, A., Macdonald, A., Dandy, E., Valenti, P. (2011). The State of Sustainability Reporting at Canadian Universities. International Journal of Sustainability in Higher Education. Vol. 12, no. 1, pp. 22-40. DOI: http:// doi.org/10.1108/14676371111098285

29. Vaughter, P., Wright, T., McKenzie, M., Lidstone, L. (2013). Greening the Ivory Tower: A Review of Educational Research on Sustainability in Post-Secondary Education. Sustainability (Switzerland). Vol. 5, no. 5, pp. 2252-2271.DOI: http://doi.org/10.3390/su5052252 
30. Mehta, N.B., Hull, A.L., Young, J.B., Stoller, J.K. (2013). Just Imagine: New Paradigms for Medical Education. Academic Medicine. Vol. 88, no. 10, pp. 1418-1423.DOI: http://doi.org/ 10.1097/ ACM.0b013e3182a36a07

31. Lahtinen, P., Leino-Kilpi, H., Salminen, L. (2014). Nursing Education in the European Higher Education Area - Variations in Implementation. Nurse Education Today. Vol. 34, no. 6, pp. 1040-1047. DOI: http://doi.org/10.1016/j. nedt.2013.09.011

32. Satu, K., Leena, S., Mikko, S., Riitta, S., Helena, L. (2013). Competence Areas of Nursing Students in Europe. Nurse Education Today. Vol. 33, no. 6, pp. 625-632. DOI: http://doi.org/ 10.10 16/j. nedt.2013.01.017

33. Popkess, A.M., McDaniel, A. (2011). Are Nursing Students Engaged in Learning? A Secondary Analysis of Data from the National Survey of Student Engagement. Nursing Education Perspectives. Vol. 32, no. 2, pp. 89-94. DOI: http:// doi.org/10.5480/1536-5026-32.2.89

34. Smith, R.A., Khawaja, N.G. (2011). A Review of the Acculturation Experiences of International Students. International Journal of Intercultural Relations. Vol. 35, no. 6, pp. 699-713. DOI: http://doi.org/10.1016/j.ijintrel.2011. 08.004

35. Contreras, F. (2009). Sin Papeles y Rompiendo Barreras: Latino Students and the Challenges of Persisting in College. Harvard Educational Review. Vol. 79, no. 4, pp. 610-631. DOI: http://dx.doi.org/10.17763/haer.79.4. 02671846902gl33w

36. Van Dinther, M., Dochy, F., Segers, M. (2011). Factors Affecting Students' Self-Efficacy in Higher Education. Educational Research Review. Vol. 6, no. 2, pp. 95-108. DOI: http://dx.doi. org/10.1016/j.edurev.2010.10.003

37. Aquilina, D., Henry, I. (2010). Elite Athletes and University Education in Europe: A Review of Policy and Practice in Higher Education in the European Union Member States. International Journal of Sport Policy. Vol. 2, no. 1, pp. 25-47. DOI: http://doi. org/10.1080/19406941003634024

38. Barry, A.E., Whiteman, S.D., Wadsworth, S.M. (2014). Student Service Members/Veterans in Higher Education: A Systematic Review. Journal of Student Affairs Research and Practice. Vol. 51, no. 1, pp. 30-42. DOI: http://doi. org/10.1515/jsarp-2014-0003
39. Hopkins, L. (2011). The Path of Least Resistance: A Voice-Relational Analysis of Disabled Students' Experiences of Discrimination in English Universities. International Journal of Inclusive Education. Vol. 15, no. 7, pp. 711-727. DOI: http://doi. org/10.1080/13603110903317684

40. Pino, M., Mortari, L. (2014). The Inclusion of Students with Dyslexia in Higher Education: A Systematic Review Using Narrative Synthesis. Dyslexia. Vol. 20, no. 4, pp. 346-369. DOI: http://doi.org/10.1002/dys.1484

41. Baeten, M., Kyndt, E., Struyven, K., Dochy, F. (2010). Using Student-Centred Learning Environments to Stimulate Deep Approaches to Learning: Factors Encouraging or Discouraging Their Effectiveness. Educational Research Review. Vol. 5, no. 3, pp. 243-260. DOI: http://doi. org/10.1016/j.edurev.2010.06.001

42. Seery, M.K. (2015). Flipped Learning in Higher Education Chemistry: Emerging Trends and Potential Directions. Chemistry Education Research and Practice. Vol. 16, no. 4, pp. 758-768. DOI:10.1039/c5rp00136f

43. De Rijdt, C., Stes, A., van der Vleuten, C., Dochy, F. (2013). Influencing Variables and Moderators of Transfer of Learning to the Workplace within the Area of Staff Development in Higher Education: Research Review. Educational Research Review. No. 8, pp. 48-74. DOI: http://doi. org/10.1016/j.edurev.2012.05.007

44. Broadbent, J., Poon, W.L. (2015). Self-Regulated Learning Strategies \& Academic Achievement in Online Higher Education Learning Environments: A Systematic Review. Internet and Higher Education. No. 27, pp. 1-13. DOI: http://doi. org/10.1016/j.iheduc.2015.04.007

45. Baran, E., Correia, A.-P., Thompson, A. (2011). Transforming Online Teaching Practice: Critical Analysis of the Literature on the Roles and Competencies of Online Teachers. Distance Education. Vol. 32, no. 3, pp. 421-439. DOI:10.1080/0 1587919.2011.610293

46. Evans, C. (2013). Making Sense of Assessment Feedback in Higher Education. Review of Educational Research. Vol. 83, no. 1, pp. 70-120. DOI: http://doi.org/10.3102/0034654312474350

47. Kaufman, J.H., Schunn, C.D. (2011). Students' Perceptions about Peer Assessment for Writing: Their Origin and Impact on Revision Work. Instructional Science. Vol. 39, no. 3, pp. 387406. DOI: http://doi.org/10.1007/s11251-0109133-6 
48. Torrance, H. (2012). Formative Assessment at the Crossroads: Conformative, Deformative and Transformative Assessment. Oxford Review of Education. Vol. 38, no. 3, pp. 323-342. doi:10.108 $0 / 03054985.2012 .689693$

49. Nulty, D.D. (2011). Peer and Self-Assessment in the First Year of University. Assessment and Evaluation in Higher Education. Vol. 36, no. 5, pp. 493-507. DOI: http://doi.org/10.1080/ 02602930903540983

50. Joughin, G. (2010). The Hidden Curriculum Revisited: A Critical Review of Research into the Influence of Summative Assessment on Learning. Assessment and Evaluation in Higher Education. Vol. 35, no. 3, pp. 335-345. DOI: http://doi. org/10.1080/02602930903221493

51. van Lankveld, T., Schoonenboom, J., Volman, M., Croiset, G., Beishuizen, J. (2017). Developing a Teacher Identity in the University Context: A Systematic Review of the Literature. Higher Education Research and Development. Vol. 36, no. 2, pp. 325-342. DOI: http://doi.org/10.1080/07294360.2 016.1208154

52. Brew, A. (2010). Transforming Academic Practice through Scholarship. International Journal for Academic Development. Vol. 15, no. 2, pp. 105-116. DOI: http://doi.org/10.1080/ 13601441003737618

53. Evans, M.P. (2013). Educating Preservice Teachers for Family, School, and Community Engagement. Teaching Education. Vol. 24, no. 2, pp. 123-133. DOI: http://doi.org/10.1080/10476210 .2013 .786897

54. Bennett, D. (2009). Academy and the Real World: Developing Realistic Notions of Career in the Performing Arts. Arts and Humanities in Higher Education. Vol. 8, no. 3, pp. 309-327. DOI: http://doi.org/10.1177/1474022209339953

55. Spooren, P., Brockx, B., Mortelmans, D. (2013). On the Validity of Student Evaluation of Teaching: The State of the Art. Review of Educational Research. Vol. 83, no. 4, pp. 598-642. DOI: http://doi.org/10.3102/0034654313496870

56. Smit, U., Dafouz, E. (2012). Integrating Content and Language in Higher Education: An Introduction to English-Medium Policies, Conceptual Issues and Research Practices Across Europe. AILA Review. Vol. 25, no. 1, pp. 1-12. DOI: http://doi.org/10.1075/aila.25.01smi

57. Jonsson, A. (2013). Facilitating Productive Use of Feedback in Higher Education. Active Learning in Higher Education. Vol. 14, no. 1, pp. 63-76. DOI: http://doi.org/10.1177/1469787412467125

58. Gabelica, C., den Bossche, P.V., Segers, M., Gijselaers, W. (2012). Feedback, a Powerful Lever in Teams: A Review. Educational Research Review. Vol. 7, no. 2, pp. 123-144. DOI: https://doi. org/10.1016/j.edurev.2011.11.003

59. Alderman, L., Towers, S., Bannah, S. (2012). Student Feedback Systems in Higher Education: A Focused Literature Review and Environmental Scan. Quality in Higher Education. Vol. 18, no. 3, pp. 261-280. DOI: http://doi.org/10.1080/135 38322.2012.730714

60. Tomlinson, M. (2012). Graduate Employability: A Review of Conceptual and Empirical Themes. HigherEducation Policy. Vol. 25, no. 4, pp. 407431. DOI: http://doi.org/10.1057/hep.2011.26

61. Helyer, R. (2011). Aligning Higher Education with the World of Work. Higher Education, Skills and Work-Based Learning. Vol. 1, no. 2, pp. 95-105. DOI: http://doi.org/10.1108/ 20423891111128872

62. Persson, M. (2015). Education and Political Participation. British Journal of Political Science. Vol. 45, no. 3, pp. 689-703. DOI: http://doi. org/10.1017/S0007123413000409

63. Connaway, L.S., Lewis, J.S., Alexander, S., Du, Y., Eden, B., Petersohn, B., Proffitt, M. \& Salisbury, L. (2012). 2012 Top Ten Trends in Academic Libraries: A Review of the Trends and Issues Affecting Academic Libraries in Higher Education. College and Research Libraries News. Vol. 73, no. 6, pp. 311320. DOI: http://doi.org/10.5860/crln.73.6.8773

64. Kezar, A. (2011). What is the Best Way to Achieve Broader Reach of Improved Practices in Higher Education? Innovative Higher Education. Vol. 36, no. 4, pp. 235-247. DOI: http://doi. org/10.1007/s10755-011-9174-z

65. Knight, J. (2011). Education Hubs: A Fad, a Brand, an Innovation? Journal of Studies in International Education. Vol. 15, no. 3, pp. 221-240. DOI: http://doi.org/10.1177/1028315311398046

66. Bearman, M., Smith, C. D., Carbone, A., Slade, S., Baik, C., Hughes-Warrington, M., Neumann, D. L. (2012). Systematic Review Methodology in Higher Education. Higher Education Research and Development. Vol. 31, no. 5, pp. 625-640. DOI: http://doi.org/10.1080/07294360.2012.702735

Статья поступила в редакцию 10.01.20 После доработки 29.01.20 Принята к публикачии 15.02.20 


\section{An Overview of Reviews as a Trend Maker in the Field}

Lilia K.Raitskaya - Dr. Sci. (Education), e-mail: raitskaya.1.k@inno.mgimo.ru Moscow State Institute of International Relations (MGIMO University), Moscow, Russia Address: 76, prospect Vernadskogo, Moscow, 119454, Russian Federation ElenaV.Tikhonova - Cand. Sci. (History), e-mail: etihonova@gmail.com Peoples' Friendship University of Russia (RUDN University), Moscow, Russia Address: 6, Miklukho-Maklaya str., Moscow, 117198, Russian Federation Russian Academy of Education, Moscow, Russia Address: 8, Pogodinskaya str., Moscow, 119121, Russian Federation

Abstract. The authors consider the methodology basics of reviews as a prospective type of scholarly publications, their taxonomy and most popular review types (narrative reviews, bibliometric reviews, systematic reviews, reviews of reviews, scoping reviews, meta-analysis), as well as specific features of procedures and algorithms for conducting reviews. Top 100 of highly cited reviews on higher education from 2010 to 2019 published in high-ranking peer-reviewed journals and indexed in the international database Scopus is based on the traditional methodology that aims to sample the most essential and influential publications of the kind in a well-represented and unbiased way and to subject the sampled reviews to content, bibliometric, and linguistic analyses. Based on the inclusion criteria, keywords and methods of objective selection and sampling of the publications to be reviewed and analyzed, the authors singled out the essential thematic clusters in Top-100 list (educational technologies, university, student, teaching, learning, assessment, etc.) and determined the key directions in the review field of study. Each cluster contains a brief description of the most important aspects and approaches to various topics related to higher education, an analysis of their novelty and existing gaps in the field. According to the rhetoric theory of scholarly text by John Swales named 'Moves and steps', the authors offer a uniform rhetoric schema of reviews, commenting on the text components and their contents. Such a schema may serve as a guideline for authors of reviews made up for international peer-reviewed journals. The most popular publications by citations and number of publications entail reviews devoted to the culture of higher education; educational technologies and peculiarities of their application in the new educational landscape; online education as a new dimension of education requiring a special ecosystem; academic ethics of university teachers; soft skills development necessary for successful professional development; academic and scientific libraries as new centers for scientific and academic communication.

Keywords: review, systematic review, scoping review, bibliometric review, theoretical review, descriptive review, narrative review, higher education, university, learning, technologies

Cite as: Raitskaya, L.K., Tikhonova, E.V. (2020). An Overview of Reviews as a Trend Maker in the Field. Vysshee obrazovanie v Rossii = Higher Education in Russia. Vol. 29, no. 3, pp. 37-57. (In Russ., abstract in Eng.)

DOI: https://doi.org/10.31992/0869-3617-2020-29-3-37-57 